\title{
Direct Evidence for Main Chain Scissions of Polymers in Solution Caused by High Speed Stirring
}

\author{
Masayoshi Tabata, Yoichi HosoKAWA,* Osamu WATANABE, ** \\ and Junkichi SOHMA \\ Faculty of Engineering, Hokkaido University, Sapporo, 060 Japan \\ * Research and Development Laboratory, Mitsui Cynamid Ltd. \\ Yokohama, Kanagawa, Japan \\ ** Kawamura Physical and Chemical Research Laboratory, \\ Urawa, Saitama, Japan
}

(Received March 24, 1986)

\begin{abstract}
Mechanical degradation of polymers in soluiton caused by high speed stirring was investigated in order to obtain unequivocal direct information for main-chain scissions of polymers using ESR method combined with a spin trapping technique. It is interesting to know whether or not such main-chain scission radicals with short lifetimes can be stabilized by pentamethylnitrosobenzene (PMNB), as a spin trapping reagent forming a nitroxide radical. Several polymers in benzene solution added with PMNB were agitated by a high speed stirring in nitrogen atmosphere and ESR spectra obtained were analyzed. The analysis of ESR spectra from the nitroxide radicals called spin adducts enabled us to obtain information on main-chain scissions of several polymers, for example, poly(styrene) (PSt), poly $(\alpha$-methylstyrene) (Poly- $\alpha$-MeSt), poly(methyl methacrylate) (PMMA), poly(vinyl acetate) (PVAc), poly(ethylene glycol) (PEG) and poly(styrene- $c o-\alpha$-methylstyrene). In the case of the random copolymer of poly(styrene-co- $\alpha$ methylstyrene), it was suggested that broken bonds were formed not in the repeating styrene units but those of $\alpha$-methylstyrene units.
\end{abstract}

KEY WORDS Mechanical Degradation / Main-Chain Scission / MechanoChemistry / Poly(methyl methacrylate) / Polystyrene / Poly(vinyl acetate) / Poly(ethylene glycol) / High Speed Stirring / Spin Trapping / ESR of Mechano-Radical /

It has been suggested that high speed stirring of polymer solution leads to rupture of the main-chains of polymers. ${ }^{1}$ The chain scissions were evidenced by decrease of molecular weight observed after the agitation. ${ }^{2}$ A capture of a formed radical was also tried by the use of radical scavengers, such as iodine and 1, 1diphenyl-2-pycryl-hydrazyl (DPPH) ${ }^{4}$ in nitrogen atmosphere and the consumption rates of these scavengers were monitored. However, the methods seem not so useful to obtain direct and more detailed information about specific broken points of either main chains or side chains. Therefore, the spin trapping technique was employed to stabilize the unstable scission radicals. Several synthetic polymers in benzene solution were agitated in the presence of a spin trapping reagent, pentamethylnitrosobenzene (PMNB), and analyses of observed ESR spectra from nitroxide radicals formed were confirmed by the aid of a partially deuterated polymer sample and computer simulations. In this communication, various reactions, such as direct main-chain scission, a $\beta$-scission and a hydrogen abstraction of polymers caused by the high speed stirring will be evidenced together with mechanism of polymer degradation induced by high speed stirring. 


\section{EXPERIMENTAL}

\section{Apparatus}

To agitate polymer solution in an atmosphere of nitrogen a special apparatus was designed in our laboratory. ${ }^{5}$ The apparatus used is shown in Figure 1. The maximum rotational frequency of this stirrer was approximately $1.4 \times 10^{4} \mathrm{rpm}$. The frequency was exactly checked by a rotation calibrator equipped with a phototransistor. The stirrer was purged with highly purified nitrogen gas, $99.999 \%$ before used. Benzene solution (2 $\mathrm{ml}$ ) containing a known weight of each polymer and PMNB was prepared in the ESR sample tube and impurity gas in the solution was removed by repeated thawing and freezing using vacuum line at $10^{-4}$ Torr. After that, the sample tube was connected with the glass ampoule unit replaced with $\mathrm{N}_{2}$ in advance, as depicted in Figure 1. The polymer solution subjected to the high speed stirring in the presence of PMNB was transferred in the ESR sample tube to observe ESR spectra.

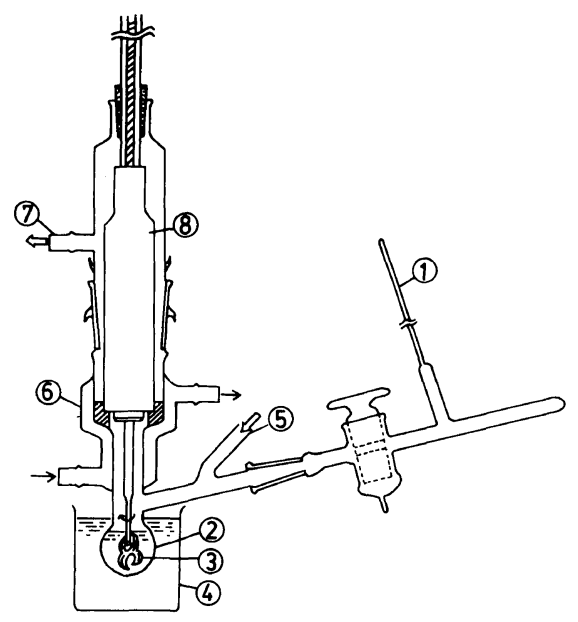

Figure 1. Apparatus for high speed stirring experiment. 1) ESR sample tube; 2) reactor made of glass in which a sample is contained; 3 ) high speed rotating blade made of stainless steel; 4) water bath for controlling temperature of sample; 5 ) inlet of gas, thick arrows mean a flow of nitrogen gas filling the whole vessel; 6) condenser to prevent evaporation of a solvent; 7) - ; 8) a rotor.
The ESR spectrometer used was a JEOLJESPE with $100 \mathrm{kHz}$ modulation. Simulations of observed ESR spectra were performed using a modified Maruani's Program. ${ }^{6}$

\section{MATERIALS}

\section{Commercial Polymers}

Poly(methyl methacrylate) (PMMA), poly(styrene) (PSt), poly( $\alpha$-methylstyrene) (Poly$\alpha-\mathrm{MeSt}$ ), poly(vinyl acetate) (PVAc) and poly(ethylene glycol) (PEG) manufactured by Wako Pure Chemical Co., Ltd., were used after triple precipitations and drying. Random copolymer of St and $\alpha$-MeSt supplied by Mitsui Petroleum Co., Ltd., was used. The composition of the copolymer was determined as $\mathrm{St}: \alpha-\mathrm{MeSt}=66: 34$ using an ${ }^{1} \mathrm{H}$ NMR spectrometer. Alpha-deuterated styrene monomer was synthesized according to Wall's method, ${ }^{7}$ followed by polymerization using bensoylperoxide as a radical initiator. A spin trapping reagent, PMNB, was prepared according to the literature. ${ }^{8}$ Decrease of molecular weight of polymers after stirring was measured as a function of time.

\section{RESULTS AND IDENTIFICATIONS OF RADICALS}

\section{PMMA}

Figure 2a shows an ESR spectrum observed at room temperature from the sample of PMMA-benzene solution (100 mg, 2 ml) containing the PMNB $(0.5 \mathrm{mg})$ after stirring for 20 minutes at $20^{\circ} \mathrm{C}$ on $14000 \mathrm{rpm}$. This spectrum was decomposed into two components, a triple triplet and a triplet, as shown by the stick diagrams. The triplet having the coupling constant of $13.3 \mathrm{G}$ for one nitrogen was assigned to a spin adduct generated from a tertiary carbon radical. The triple triplet having the coupling constants of $13.3 \mathrm{G}$ for one nitrogen and $8.2 \mathrm{G}$ for two protons was assigned to a spin adduct of a primary carbon radical. Spectrum simulation was carried 

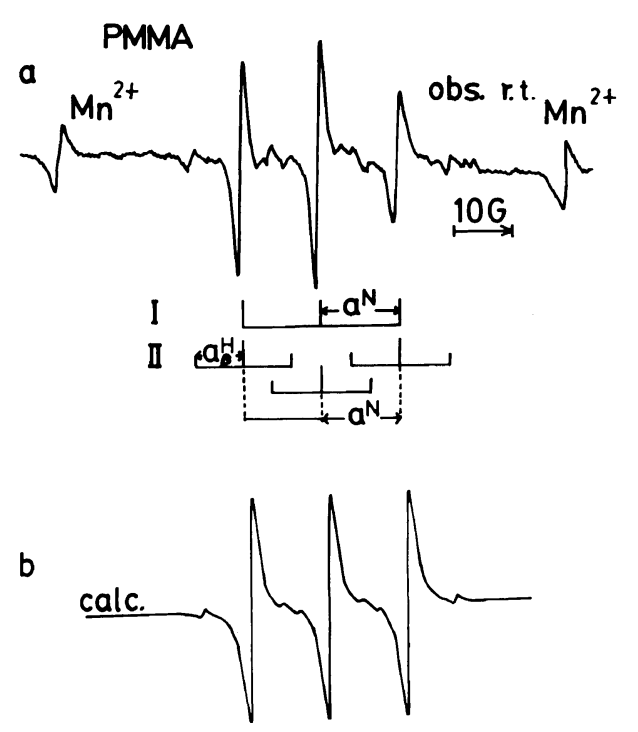

Figure 2. a: ESR spectrum observed from benzene solution of PMMA and PMNB at room temperature after the high speed stirring. b: Simulated spectrum based on a superposition a triplet and a triple triplet.

out by superposition of two components and a simulated spectrum is shown in Figrue $2 b$. Coincidence between the observed spectrum and the simulated one was satisfactory.

Three different species of tertiary carbon radicals could be generated from the mother molecule, PMMA:<smiles>CCCCCC(CCCC(C)CC)C(=O)OC</smiles><smiles>CCC(C)C(=O)OC</smiles>

Radical species $(C)$ is a mian-chain scission radical and another species $(\mathrm{A})$ and $(\mathrm{B})$ are side-chain scission radicals. If the side-chains of PMMA were ruptured by the high speed stirring to form either a methyl radical or a methyl ester radical together with the radicals $A$ and B, the PMNB could capture all these radicals. In fact, the ESR spectrum of the PMNB spin adduct generated from the methyl radical was observed by Doba et al. ${ }^{9}$ However, no methyl radical was detected in this stirring experiment. No detection of the methyl radical suggests no formation of a partner radical (B) of the methyl radical. Since the methyl ester radical is instantly decomposed into carbon dioxide and methyl radical, the lack of detection of methyl radical also suggests that no methyl ester radicals are generated by the high speed stirring. Thus it is safe to assume that the partner radical $(\mathrm{A})$ is not produced by the high speed stirring. Moreover, it is reasonable to consider that no sidechain scission can be caused by the high speed stirring. Therefore, one can conclude that the observed triplet originates from the spin adduct of the radical (C) generated by the high speed stirring.

Three different species of primary carbon radicals could be generated from the mother molecule, PMMA;

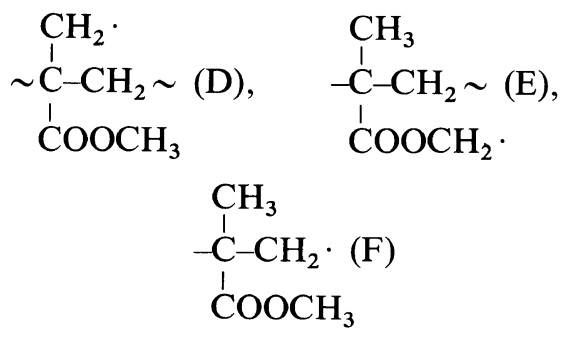

The radical species (F) is a main-chain scission radical and another species (D) and (E) are generated by the hydrogen abstraction from either methyl or ester methyl groups. Figure 3a shows an ESR spectrum observed from ester methyl deuterated PMMA in a benzene solution containing the PNMB under the same experimental conditions. No change in the main character of the spectrum was observed from ester methyl dueterated PMMA. Therefore, the possibility that the radical species (E) could be responsible for the observed triple triplet is ruled out. Tabata et al. ${ }^{11}$ have identified the main-chain scission radicals of PMMA, the radical species (C) and (F), induced by ultrasonic irradiation of 

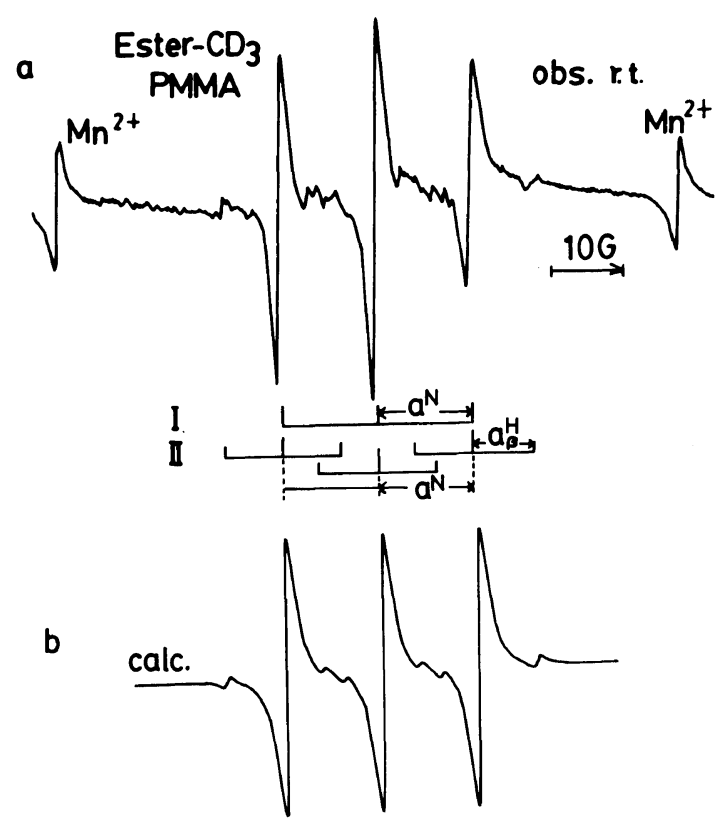

Figure 3. a: ESR spectrum observed from benzene solution of ester deuterated PMMA and PMNB at room temperature after the high speed stirring. b: simulated spectrum based on a superposition of a triplet and a triple triplet.
PMMA benzene solution in the presence of PMNB. The coupling constants repoted in their study are the same as those shown in Figure $2 \mathrm{a}$ within experimental error. Thus, it is reasonably concluded that the triple triplet is attributed to the spin adducts of radical $(F)$. Since the radical $(C)$ is the partner radical of the radical $(F)$, the pair formation of these radicals is positive evidence for the main chain scission induced by stirring.

\section{PSt}

Figure 4a shows an ESR spectrum observed from the sample of PSt-benzene solution under the same experimental conditions. This spectrum is decomposed into two components, a double triplet and a triple triplet, as shown with the stick diagrams. The duble triplet haing the coupling constants of $13.8 \mathrm{G}(1 \mathrm{~N})$ and $4.3 \mathrm{G}(1 \mathrm{H})$ was assigned to the spin adduct of a secondary carbon radical. The triple triplet having the coupling constants of $13.4 \mathrm{G}$ (1N) and $8.5 \mathrm{G}(2 \mathrm{H})$ was assigned to the spin
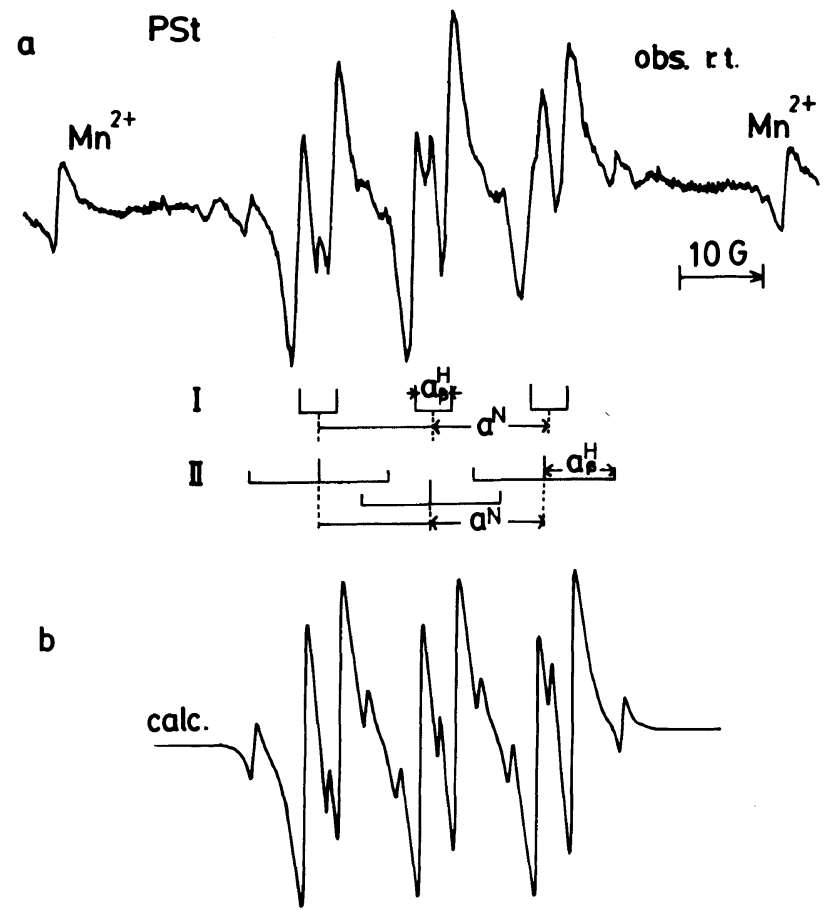

Figure 4. a: ESR spectrum observed from benzene solution of PSt and PMNB at room temperature after high speed stirring. b: Simulated spectrum based on superposition of a double triplet and triple triplet. 
adduct of a primary carbon radical. Figure $4 \mathrm{~b}$ shows a simulated spectrum superposed of theoretical spectra of the two components.

The primary carbon radical generated from mother molecule, PSt, is a single species.<smiles>Cl[C@H](Cc1ccccc1)c1ccccc1</smiles>

Three different species of secondary carbon radicals could be generated from PSt.

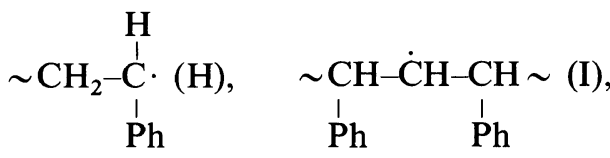

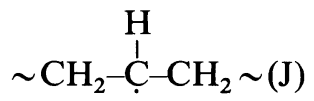

A PMNB spin adduct of phenyl radical was observed by Doba et al. ${ }^{9}$ and Tabata and Sohma, ${ }^{12}$ but in this experiment it was not observed. No detection of the spin adduct of the phenyl radical suggests no formation of its partner radical, that is the radical $(\mathrm{J})$. In order to determine which species $(\mathrm{H})$ or (I) is responsible for the observed spectrum, $\alpha$ deuterated polystyrene $\left(\alpha-d_{1}\right.$-PSt) was used under the same experimental conditions. Figure 5a shows an ESR spectrum observed from $\alpha-d_{1}$-PSt-benzene solution after the stirring. This spectrum is decomposed into two components, a triplet and a triple triplet. Comparison of the spectra shown in Figure 4a and Figure 5a indicates that the double triplet changed into the triplet but the triple triplet was unvaried by replacement of the $\alpha$ proton in PSt with a deuterium. Therefore, it is concluded that the secondary carbon radical generated from high speed stirring of PSt-benzene solution is attributed to the radical $(\mathrm{H})$. Thus, the pair formation of the radical $(G)$ and $(H)$ is proved by the spintrapping technique and this is also positive evidence of the main chain scission of PSt caused by high speed stirring.
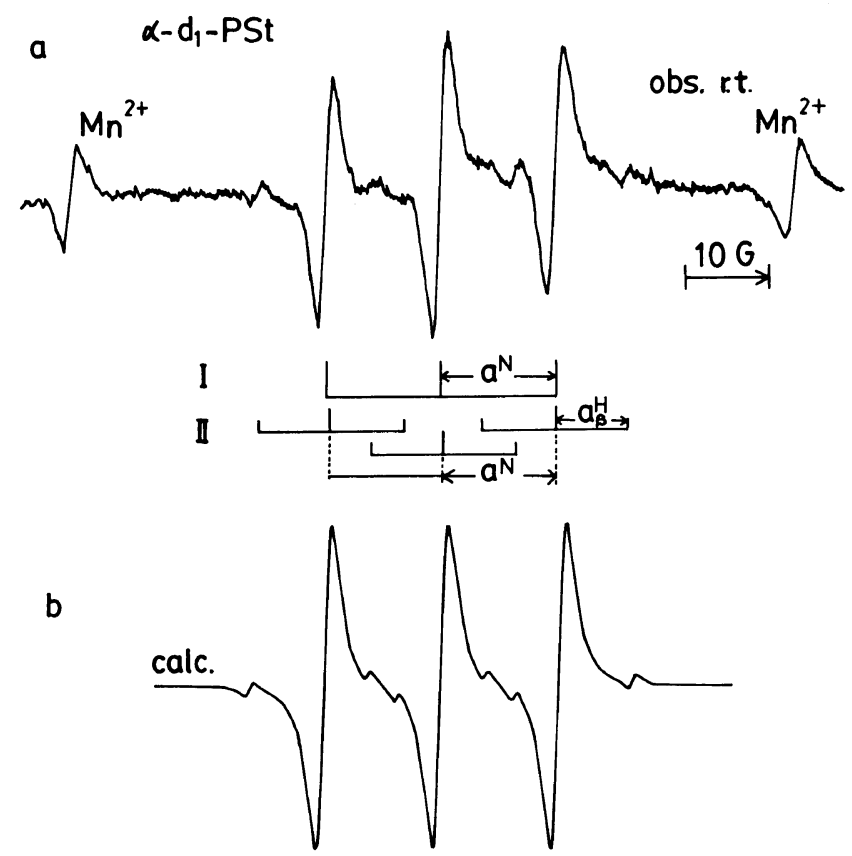

Figure 5. a: ESR spectra observed from benzene solution of deuterated PSt and PMNB under the same conditions in Fig. 4. b: Simulated spectrum based on superposition of a triplet and triple triplet. 

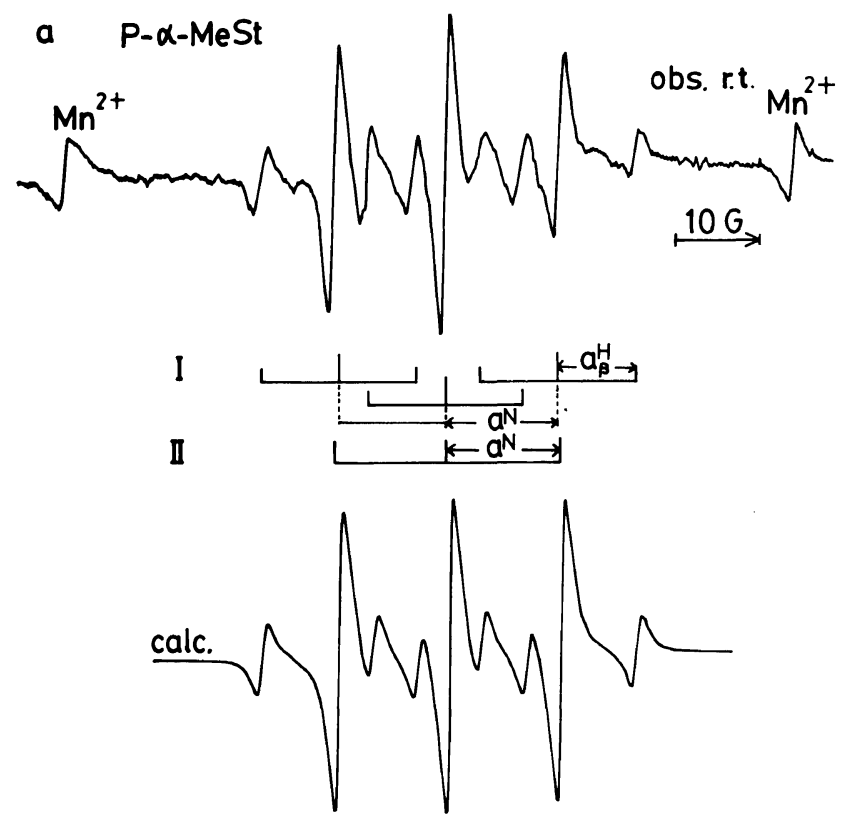

Figure 6. a: ESR spectrum observed from benzene solution of Poly- $\alpha-\mathrm{MeSt}$ and PMNB at room temperature after high speed stirring. b: Simulated spectrum based on superposition of a triple triplet and triplet.

\section{Poly- $\alpha-M e S t$}

Figure 6a shows an ESR spectrum observed at room temperature from the sample of Poly$\alpha$-MeSt after the stirring. This spectrum consists of two components, a triplet and a triple triplet as shown by stick diagrams. The triplet having the coupling constants of $13.4 \mathrm{G}(1 \mathrm{~N})$ was assigned to a spin adduct of a tertiary carbon radical. The triple triplet having the coupling constants of $13.0 \mathrm{G}(1 \mathrm{~N})$ and $9.2 \mathrm{G}$ (2H) was assigned to a spin adduct of a primary carbon radical. Figure $6 \mathrm{~b}$ shows a simulated spectrum by superposition of the two components.

Three different species of tertiary carbon radicals could be generated from Poly- $\alpha-\mathrm{MeSt}$ :<smiles>CCC(C)(CC)CCC(C)(C)c1ccccc1</smiles>

No detection of both the methyl radical and the phenyl radical suggest no formation of their partner radicals, (L) and (M), by reasons similar to the above. Therefore, it is concluded that the observed triplet originates from the spin adduct of radical species (K). Two different species of primary carbon radicals could be generated from Poly- $\alpha$-MeSt<smiles>CCC(C)(CC#N)c1ccccc1</smiles>

Since the radical species $(\mathrm{K})$ was identified, it is reasonable to assume the presence of the partner radical, that is, the species (O). Thus, the experimental results can be interpreted as trapping of the pair radicals $\mathrm{K}$ and $\mathrm{O}$ by the PMNB, as in the case of PMMA and PSt.

\section{$P V A c$}

Figure 7a shows an ESR spectrum observed at room temperature from the sample of 


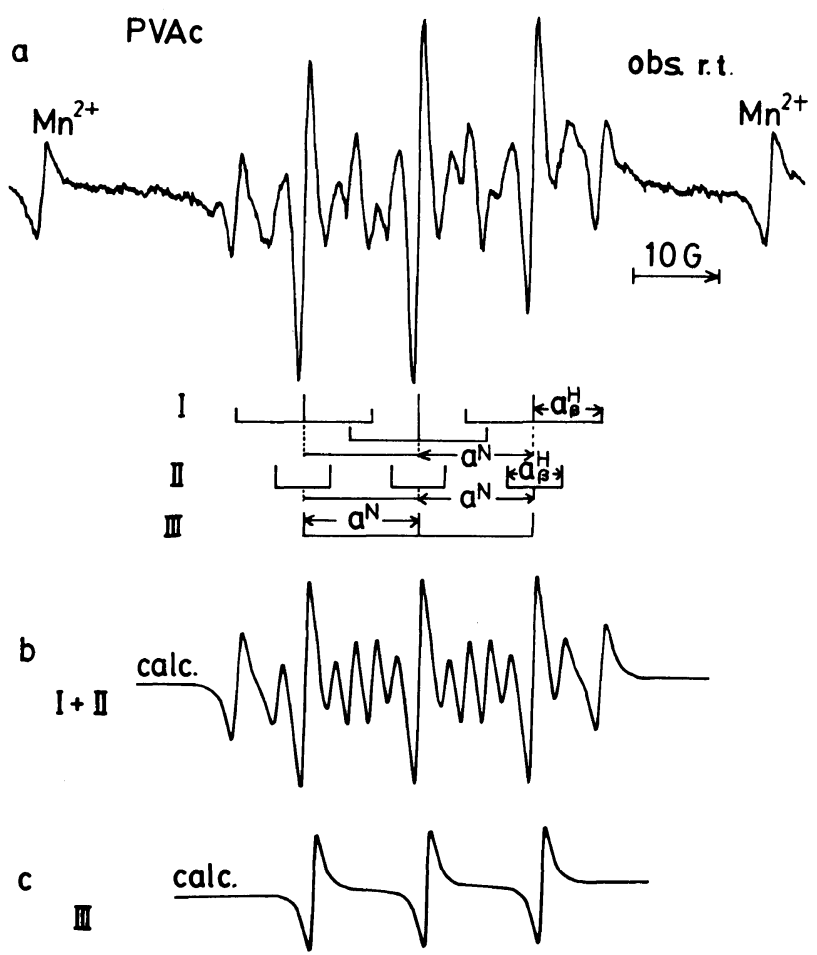

Figure 7. a: ESR spectrum observed from a benzene solution of PVAc and PMNB at the room temperature after high speed stirring. $b$ and $c$ : Simulated spectra based on superposition of a triple triplet and double triplet (b) and triplet (c).

PVAc benzene solution after stirring. This spectrum consists of three components, a triplet, a double triplet, and a triple triplet, as shown by stick diagrams. The triplet having the coupling constants of $13.7 \mathrm{G}(1 \mathrm{~N})$, the double triplet having those of $13.7 \mathrm{G}(1 \mathrm{~N})$ and $6.4 \mathrm{G}(1 \mathrm{H})$, and the triplet triplet having the $13.7 \mathrm{G}(1 \mathrm{~N})$ and $8.1 \mathrm{G}(2 \mathrm{H})$ were assigned to spin adducts of tertiary, secondary, and primary carbon radicals, respectively. Figure 7 b shows a simulated spectrum by superposition of a double triplet and a triple triplet and Figure 7c shows a simulated one for the triplet.

Two different species of the primary carbon radicals could be generated from the PVAc

$$
\begin{array}{r}
\sim \mathrm{CH}_{2}-\underset{1}{\mathrm{CH}-\mathrm{CH}_{2}} \cdot \\
\mathrm{OCOCH}_{3}
\end{array}
$$

$$
\begin{gathered}
\sim \mathrm{CH}_{2}-\underset{\text { l }}{\mathrm{CH}-\mathrm{CH}_{2} \sim(\mathrm{Q})} \\
\mathrm{OCOCH}_{2} .
\end{gathered}
$$

Three different species of the secondary carbon radicals could be generated from the PVAc<smiles>CCCCC(=O)C(C)OC(C)=O</smiles>

The results from the previous experiments for the PMMA, PSt, Poly- $\alpha-\mathrm{MeSt}$ lead one to believe that the main-chains of this polymer, PVAc, were primarily ruptured by stirring to produce the main-chain scission radicals. It 
a

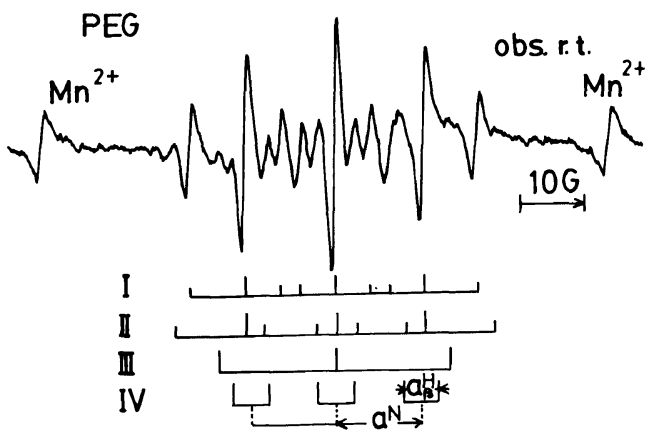

b I+IV

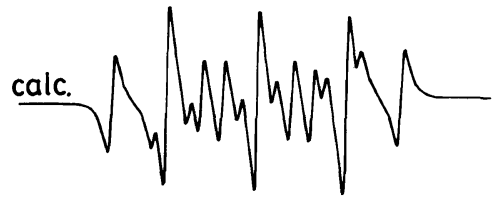

c II+II calc. $>M$

Figure 8. a: ESR spectrum observed from a benzene solution of PEG and PMNB at room temperature after high speed stirring. $b$ and c: Simulated spectra based on superposition of a triple triplet and double triplet (b) and a triple triplet and triplet (c).

is no contradiction with the experimental results, if the main-chains are scissioned by stirring in the case of PVAc. Then, radicals (P) and (T) are assumed to be chosen among the five possible species for the radicals responsible for the observed spectrum. The tertiary carbon radical generated from PVAc is a single species

$$
\begin{array}{r}
\sim \mathrm{CH}_{2}-\underset{\mathrm{C}}{\mathrm{C}}-\mathrm{CH}_{2} \sim \\
\mathrm{OCOCH}_{3}
\end{array}
$$

This radical $(\mathrm{U})$ is presembaly produced by a hydrogen abstraction from the $\alpha$-carbon of PVAc as a secondary prcess.

\section{PEG}

Figure 8a shows an ESR spectrum observed at room temperature from the sample of PEG-benzene solution after the stirring under the same conditions. This spectrum was very complicated so that heat treatment of the sample was carried out to simplify the
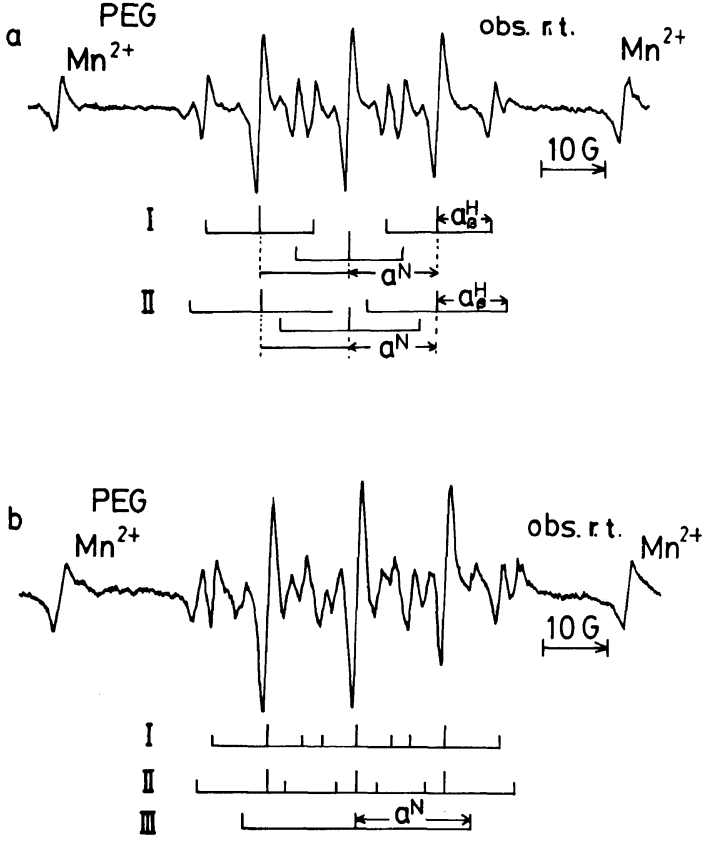

Figure 9. ESR spectra observed from benzene solution of PEG and PMNB treated at $100^{\circ} \mathrm{C}$ for 5 minutes (a) and at $90^{\circ} \mathrm{C}$ for 40 minutes after high speed stirring.

ESR spectrum. Some components among the original spectral components decayed out after heat treatment at $100^{\circ} \mathrm{C}$ for 5 minutes, so that a simplified spectrum was fortunately observed as shown in Figure 9a. This spectrum was decomposed into two components, (I) and (II) as shown by the stick diagrams. The component (I) shows a triple triplet having the coupling constants of $13.7 \mathrm{G}(1 \mathrm{~N})$ and $8.4 \mathrm{G}(2 \mathrm{H})$ and the component (II) also shows a triple triplet having those of 13.7 $\mathrm{G}(1 \mathrm{~N})$ and $11.0 \mathrm{G}(2 \mathrm{H})$. Both components (I) and (II) are attributed to spin adducts of primary carbon radicals. Two different species of the primary carbon radicals could be generated from the PEG:

$$
\begin{aligned}
& \cdot \mathrm{CH}_{2}-\mathrm{O}-\mathrm{CH}_{2} \sim(\mathrm{V}), \cdot \mathrm{CH}_{2}-\mathrm{CH}_{2}-\mathrm{O} \sim(\mathrm{W}) \\
& \text { ( } \beta) \\
& \text { ( } \beta)
\end{aligned}
$$

The magnitude of hyperfine splitting for $\beta$ protons was affected by factors such as dihedral angle between $P_{z}$ orbital on a nitro- 
gen atom and $\mathrm{a}_{\beta}-\mathrm{H}$ bond, and spin density on a nitrogen atom. In our case, two $\beta$-protons are equally coupled so that the two protons freely rotate about the $\mathrm{N}-\mathrm{C}$ bond. Therefore, the effect of dihedral angle can be ruled out. Generally, electron attracting groups such as carbonyl, phenyl, hydroxy and alkoxy exert a lowering effect of $\beta$-proton coupling constant, namely decrease of spin density on an unpaired electron center. For example, the $\beta$-proton coupling constants for the spectra of PMNB- $\mathrm{CH}_{2}-\mathrm{CH}_{3}$ and $\mathrm{PMNB}-\mathrm{CH}_{2}-\mathrm{CH}_{2}-\mathrm{CH}_{3}$ are $11.6 \mathrm{G}$ and $11.2 \mathrm{G}$, respectively, but those for the spectra of PMNB- $\mathrm{CH}_{2} \mathrm{C}_{6} \mathrm{H}_{4} \mathrm{Cl}$ and PMNB- $\mathrm{CH}_{2}-$ $\mathrm{C}_{6} \mathrm{H}_{5}$ are $8.4 \mathrm{G}$ and $8.8 \mathrm{G}$, respectively. ${ }^{13}$ The radical (V) has a higher electron attracting group combined with the $\beta$-carbon $\left(\sim \mathrm{CH}_{2}-\right.$ $\left.\mathrm{O}-\mathrm{CH}_{2} \sim\right)$ than that of radical (W) $\left(\cdot \mathrm{CH}_{2}-\right.$ $\mathrm{CH}_{2} \mathrm{O} \sim$ ). Consequently, the $\beta$-proton cou- pling constant for the spin adduct of radical (V) may be smaller than that of radical (W). Thus, it is concluded that the components (I) and (II) are attributed to the spin adduct of radicals $(\mathrm{V})$ and $(\mathrm{W})$, respectively.

After heat treatment of the stirred sample at $90^{\circ} \mathrm{C}$ for 40 minutes, the ESR spectrum as shown in Figure 9b was observed at room temperature. This spectrum consists of three components, (I), (II), and (III). The components (I) and (II) are the same as those as shown in Figure 9a. The components (III) with the coupling constant of $17.6 \mathrm{G}(1 \mathrm{~N})$ was assigned to a spin adduct of tertiary carbon radical. Previously Terabe et al. observed ESR spectra from spin adducts induced by photolysis of halogenated compound in benzene solution in the presence of the spin trapping agent, nitrosodurene. ${ }^{14}$ In their report, a spin adduct derived from $t$-BuO.

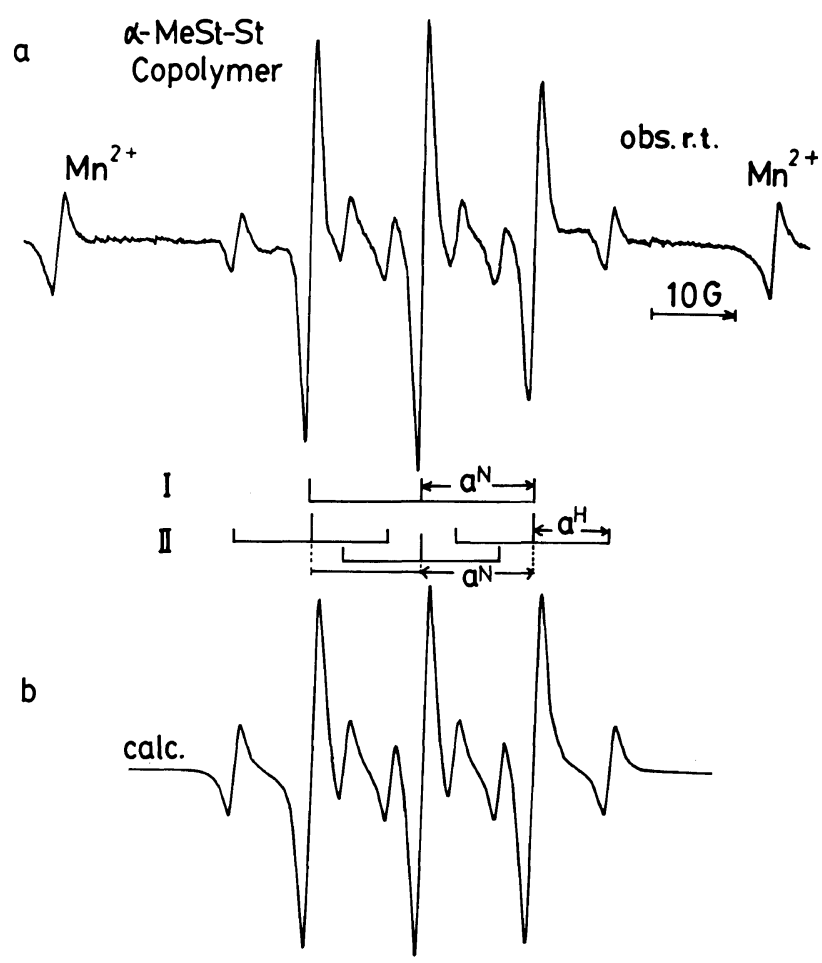

Figure 10. a: ESR spectrum observed from a benzene solution of St- $\alpha-\mathrm{MeSt}$ copolymer and PMNB at room temperature after high speed stirring. b: Simulated spectrum based on superposition of a triplet and triple triplet. 
Showed a large nitrogen coupling constant, 25. $18 \mathrm{G}$. This indicates that the nitrogen coupling constant for the spin adduct of oxyradical like $t$ - $\mathrm{BuO}$. is larger than the case of a normal carbon radical. The nitrogen coupling constant for the component (III) is also larger than that of spin adduct generated from the normal carbon radical. Therefore, it is reasonably assumed that the component (III), the triplet, is attributed to the spin adduct of oxy-radical. The oxy-radical generated from PEG uniquely was determined as

$$
\text { - } \mathrm{O}-\mathrm{CH}_{2}-\mathrm{CH}_{2} \sim
$$

The spectrum shown in Figure 8a involves not only these three components (I), (II), and (III), but also the other component (IV), a doulbe triplet with the coupling constant of 13.0 G (1N) and 5.4 G (1H). The component (IV) was attributed to a spin adduct of a secondary carbon radical generated from PEG.

$$
\sim \mathrm{O}-\dot{\mathrm{C}} \mathrm{H}-\mathrm{CH}_{2}-\mathrm{O} \sim
$$

Thus, four radical species (V), (W), (X), and

Table I. Radical species, hyperfine splitting constant, $g$-value and relative concentration ratio

\begin{tabular}{|c|c|c|c|c|c|}
\hline Polymer & Trapped radical & $g$-value & $a^{N} / \mathrm{G}$ & $a^{H} / \mathrm{G}$ & Concetration ratio \\
\hline \multirow[t]{2}{*}{ PMMA } & $\begin{array}{l}\mathrm{CH}_{3} \\
\cdot \mathrm{I}-\mathrm{CH}_{2} \sim \\
\mathrm{COOCH_{3 }} \\
\mathrm{CH}_{3}\end{array}$ & 2.0062 & 13.3 & - & 1.5 \\
\hline & $\cdot \stackrel{\mathrm{CH}_{2}-\underset{\mathrm{C}}{\mathrm{C}} \sim}{\stackrel{\mathrm{COOCH}}{3}}$ & 2.0063 & 13.3 & 8.3 & 1.0 \\
\hline PSt & $\begin{array}{l}\cdot \mathrm{CHPh}-\mathrm{CH}_{2} \sim \\
\cdot \mathrm{CH}_{2}-\mathrm{CHPh} \sim\end{array}$ & $\begin{array}{l}2.0063 \\
2.0064\end{array}$ & $\begin{array}{l}13.8 \\
13.4\end{array}$ & $\begin{array}{l}4.3 \\
8.5\end{array}$ & $\begin{array}{l}3.0 \\
1.0\end{array}$ \\
\hline \multirow[t]{2}{*}{ Poly- $\alpha-M e S t$} & $\begin{array}{l}\mathrm{CH}_{3} \\
\cdot \stackrel{\mathrm{C}}{\mathrm{C}}-\mathrm{CH}_{2} \sim \\
\mathrm{Ph}\end{array}$ & 2.0063 & 13.4 & - & 1.0 \\
\hline & $\begin{array}{c}\mathrm{CH}_{3} \\
\cdot \mathrm{CH}_{2}-\underset{I}{\mathrm{C}} \sim \\
\stackrel{\mathrm{COOCH}}{\sim}\end{array}$ & 2.0063 & 13.0 & 9.2 & 2.0 \\
\hline \multirow[t]{3}{*}{ PVAc } & $\cdot \mathrm{CH}-\mathrm{CH}_{2} \sim$ & 2.0058 & 13.7 & 6.4 & 1.0 \\
\hline & $\begin{array}{l}\mathrm{CH}_{2}-\mathrm{CH}_{1} \sim \\
\mathrm{OCOCH}_{3}\end{array}$ & 2.0059 & 13.7 & 8.1 & 4.0 \\
\hline & $\begin{array}{r}\mathrm{CH}_{2}-\mathrm{C}-\mathrm{CH}_{2} \sim \\
\mathrm{OCOCH}_{3}\end{array}$ & 2.0059 & 13.7 & - & - \\
\hline \multirow[t]{4}{*}{ PEG } & $\cdot \mathrm{CH}_{2}-\mathrm{O} \sim$ & 2.0060 & 13.7 & 8.7 & 12.0 \\
\hline & - $\mathrm{CH}_{2} \mathrm{CH}_{2}-\mathrm{O} \sim$ & 2.0060 & 13.7 & 11.0 & 3.0 \\
\hline & $\cdot \mathrm{O}-\mathrm{CH}_{2} \mathrm{CH}_{2} \sim$ & 2.0060 & 17.6 & - & 1.0 \\
\hline & $\sim \mathrm{OCH}_{2}-\mathrm{CH}-\mathrm{O} \sim$ & 2.0061 & 13.0 & 5.4 & - \\
\hline \multirow{3}{*}{$\begin{array}{l}\alpha \text {-MeSt-St } \\
\quad \text { Copolymer }\end{array}$} & $\mathrm{CH}_{3}$ & & & & \\
\hline & $\begin{array}{l}\cdot \underset{1}{\mathrm{C}}-\mathrm{CH}_{2} \sim \\
\mathrm{Ph}\end{array}$ & 2.0063 & 13.6 & - & 1.0 \\
\hline & 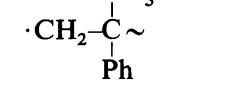 & 2.0063 & 13.2 & 9.4 & 1.0 \\
\hline
\end{tabular}
at room temperature for polymer spin adduct 
(Y) are identified.

\section{Copolymer of $\alpha$-MeSt and $S t$}

Figure 10a shows an ESR spectrum observed from the sample of copolymer in the benzene solution. This spectrum is decomposed into two components, a triplet and a triple triplet, as shown by stick diagrams. The triplet with the coupling constants of $13.6 \mathrm{G}(1 \mathrm{~N})$ and the triple triplet with those of $13.2 \mathrm{G}(1 \mathrm{~N})$ and $9.4 \mathrm{G}(2 \mathrm{H})$ were attributed to spin adducts of tertiary and primary carbon radicals, respectively.

Three different tertiary carbon radicals originates from the copolymer,<smiles>CCC(C)CCCCC(C)c1ccccc1</smiles><smiles>CCC(C)c1ccccc1</smiles>

$\mathrm{Ph}$

The radical species (l) can be generated from both a St monomer unit and $\alpha$-MeSt monomer unit. No detection of both methyl and phenyl radicals suggests no formation of their partner radicals $(\mathrm{m})$ and $(\mathrm{l})$, generated from a $\mathrm{St}$ monomer unit for reason described previously. In the case of a PSt-benzene solution, no radical species (1) was generated from a $\mathrm{St}$ monomer unit by its hydrogen abstraction from other parts of PSt chain. Thus, it is concluded that the observed triplet is attributed to the spin adduct of radical species (k).

Three different primary carbon radicals could be also generated from the copolymer.<smiles>CCC(C)(CCCCC(C)(CC)c1ccccc1)Cc1ccccc1</smiles>

But formation of the radical (n) is very unlikely for the same reason described previously. The radicals (g) and (o) are the same to the radical $(G)$ and $(O)$, respectively, in the homopolymers. The observed magnitude of the $\alpha$-proton coupling constant in this case is smaller than that of radical $(G)$ but nearly the same as the radical $(\mathrm{O})$. Therefore, it is reasonably concluded that the observed triple triplet is attributed to the spin adduct of radical (o) because of the observed value of the coupling constant. Thus, it is plausible to assume pair of partner radicals, (k) and (o), produced by main chain scission in the copolymer and styrene and $\alpha$-methylstyrene.

The trapped radicals for the polymer studied in this experiment and ESR parameter of spin adduct formed are summarized in Table I.

\section{Decrease of Molecular Weight}

Changes of number average molecular weight $\left(\bar{M}_{n}\right)$ were measured by using GPC in the case of high molecular weight PMMA in order to study molecular weight reduction induced by high speed stirring. The polymer solution was stirred with maximum speed in the ordinary atmosphere and the $\bar{M}_{n}$ was found to decrease with time at several different concentrations. The results are shown

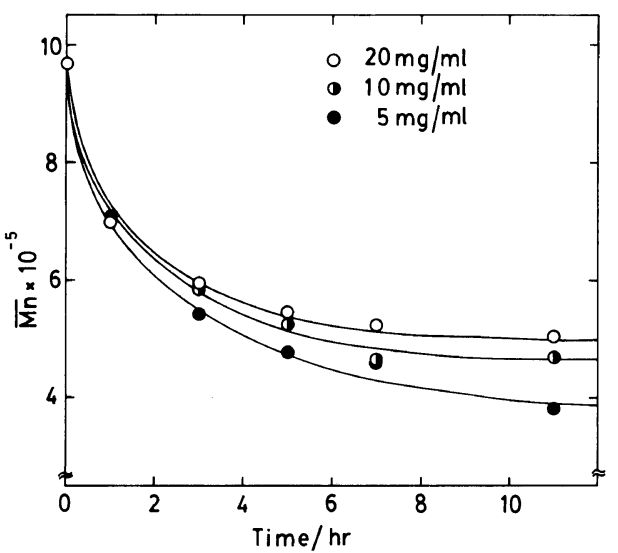

Figure 11. Change of molecular weight of PMMA as a function of time after high speed stirring in benzene solution. Each curve for the different concentrations of PMMA, O, $20 \mathrm{mg} \mathrm{ml}^{-1}$;, $10 \mathrm{mg} \mathrm{ml}^{-1}$;, $5 \mathrm{mg} \mathrm{ml}^{-1}$. 
in Figure 11. The $\bar{M}_{n}$ decreased rapidly with time and then almost leveled off. As shown in Figure 11, at a lower concentration of polymer solution, the $\bar{M}_{n}$ decreased faster. It is indicated by these experiments that a level off value for the molecular weight $\left(M_{\infty}\right)$ exists at each concentration and it was found to decrease with the decreasing concentration. When a polymer solution was stirred on $14000 \mathrm{rpm}$ in a nitrogen atmosphere, the $\bar{M}_{n}$ decreased with time and a similar tendency of the decrease of $M_{n}$ was also observed.

\section{DISCUSSION}

Pair formations of main-chain scission radicals in polymer benzene solutions were identified for several polymers as shown in Table I. These results present direct evidence of homolitic bond ruptures of polymers, namely the main-chain scissions, induced by the high speed stirring. These mainchain scission radicals may be produced by a primary effect of high speed stirring, because the trapping rate of PMNB is known to be very high. ${ }^{9}$ The relative intensity of the paired mainhain scission radicals was calculated from the obtained spectrum. The relative concentrations of the formed radicals are listed in the Table I and these are not always equal to one but not far from unity, except for PEG. This deviation from unity is explained by several causes as difference in a stability of each radical, difference of reactivity of PMNB to each radical, and different chance of the main chain scission, like the $\beta$-scission. Thus, one may believe the radicals are primarily formed as pairs by the main-chain scission, even if the relative ratio deviates from unity in some cases.

When PVAc-benzene solution was stirred on $14000 \mathrm{rpm}$, the radical species (U) attributed to tertiary carbon radical was identified except for main-chain scission radicals, $(\mathrm{P})$ and (T). Detachment of the small atom like $\mathrm{H}$ by mechanical force is hard to imagine and then the $\alpha$-hydrogen of PVAc could be abstracted by other radicals formed in the primary reaction. In other words, the radical is produced by a secondary process. Thus, degradation mechanism of PVAc induced by stirring in a liquid phase is described as follows:

$$
\begin{aligned}
& \text { PVAc }-----\infty
\end{aligned}
$$

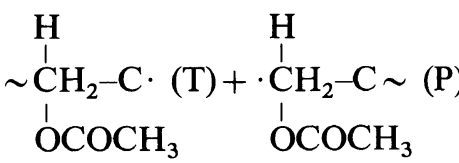

$$
\begin{aligned}
& \mathrm{R} \cdot+\mathrm{PVAc}-----\rightarrow \\
& \text { ( } \mathrm{T} \text { or } \mathrm{P} \text { ) }
\end{aligned}
$$

The radical species (P) can be produced by $\beta$ scission of radical species (U)

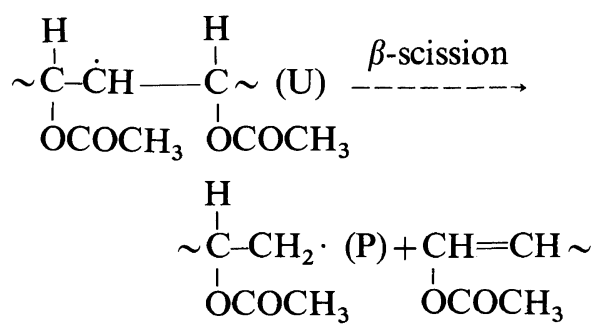

This reaction scheme also may explain the higher concentration of radical $(P)$ in the case of PVAc.

In the case of PEG, four radical species $(\mathrm{V}),(\mathrm{W}),(\mathrm{X})$, and $(\mathrm{Y})$ were identified by the analyses of ESR spectra. The radical species $(\mathrm{V}),(\mathrm{W})$, and $(\mathrm{X})$ are main chain scission radicals and the radicals $(\mathrm{W})$ and $(\mathrm{X})$ are partner radicals each other. The bond energy $\left(58.6 \mathrm{kcal} \mathrm{mol}^{-1}\right)$ and the force constant $\left(4.06 \times 10^{-5}\right.$ dyn $\left.\mathrm{cm}^{-1}\right)$ of $\mathrm{C}-\mathrm{C}$ bonds are less than those $\left(70.0 \mathrm{kcal} \mathrm{mol},^{-1} 4.96 \times 10^{-5}\right.$ dyn $\mathrm{cm}^{-1}$ ) of $\mathrm{C}-\mathrm{O}$ bond. ${ }^{15}$ The concentration of radical $(\mathrm{V})$ were three times as high as the total concentration of radical (W) and (X). This is compatible with the expectation that the weaker $\mathrm{C}-\mathrm{C}$ bond is broken more easily than the strong $\mathrm{C}-\mathrm{O}$ bond. On the 
other hand, the radical species ( $Y$ ) is produced by a hydrogen abstraction and the radicals $(\mathrm{W})$ and $(\mathrm{X})$ can be also produced by a $\beta$-scission of the radical (Y). Thus, the reaction scheme for PEG induced by the high speed stirring is described as follows:

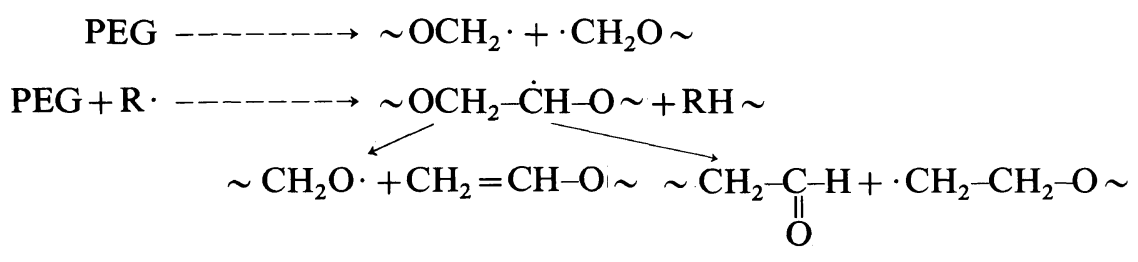

In the case of $\alpha$-MeSt and St copolymer, two main-chain scission radicals $(\mathrm{k})$ and $(\mathrm{o})$ were identified. Four possibilities of scission sites in copolymer are shcematically shown as 1,2 , 3, and 4 in Figure 12.

The polymer structures described are assumed as head to tail repeated units because it is known that head to head polymerization occurs to a small extant in the case of homopolymers. The identification of radicals described in the former section means that the chain scissions selectively occur at site 4, that is the $\alpha$-MeSt sequence, $-\mathrm{CH}_{2}-\mathrm{CHPh}-$. Thus, it should be mentioned that main-chain scissions of copolymer occur not randomly but
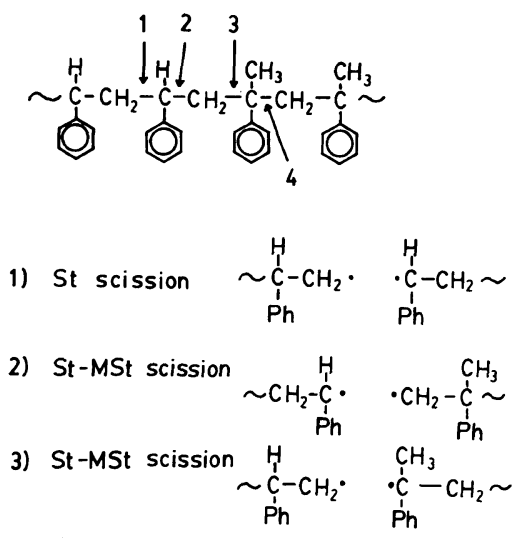

4) MSt scission

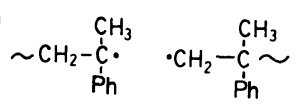

5) Other head to head structure

Figure 12. Structure of copolymer of St and $\alpha$-MeSt and expected species of radicals depending on different scission sites. preferentially in a one homopolymer sequence. The reason for this selectivity is not clear but it may be considered differences in side chain structures.

The results shown in Figure 11 demonstrate the existance of the critical molecular weights $M_{\infty}$, below which no polymer chain is ruptured by mechanical force, in the case of high speed stirring of polymer solutions. Such a critical molecular weight in the mechanical rupture of polymer chains in the solid phase was reported and explained by the simple model, ${ }^{17}$ although the critical molecular weight in the solution is as $10^{2}$ high as that in the solid. This difference might be interpreted by the fact that shearing force in a liquid phase is smaller by several orders of magnitude than that in a solid phase. It is worth noting that the critical molecular weight decreases with decrease of concentration as shown in Figure 11. It is well established that the number of entanglements of polymer chains increases with concentration and average distance between the entanglements decreases with concentration. Thus, the critical molecular weight for mechanical breakages of main chains must decrease with concentration, if the entanglements of the chains are the main cause for the main chain rupture. This is not the case. The above mentioned consideration combined with the experimental results in Figure 11 strongly suggests that entanglements of polymer chains in the polymer solution are not the predominant cause of chain scissions induced by high speed stirring. 
Acknowledgements. The authors express their thanks to Dr. Y. Saito in Gevernment Industrial Development Laboratory Hokkaido, for his permission to use the GPC instrument.

\section{REFERENCES}

1. W. Kauzman and H. Eyring, J. Am. Chem. Soc., 62, 3113 (1936).

2. R. M. Thomas, J. C. Zimmer, L. B. Turner, R. Roxen, and P. K. Frolich, Ind. Eng. Chem., 32, 299 (1940).

3. W. R. Johnson and C. C. Price, J. Polym. Sci., 45, 217 (1960).

4. W. F. Watson, G. Ayrey, and C. C. Moore, J. Polym. Sci., 19, 1 (1956).

5. M. Tabata, Y. Hosokawa, and J. Sohma, Rep. Prog. Polym. Phys. Jpn., 24, 495 (1981).

6. R. Lefevre and J. Maruani, J. Chem. Phys., 42, 1480 (1965).
7. L. A. Wall, D. W. Brown, and V. E. Hart, J. Polym. Sci., 15, 157 (1955).

8. A. Mckillop, J. S. Fowler, M. J. Zelesko, J. D. Taylor, and G. McGiluray, Tetrahedron Lett., 2423 (1969).

9. T. Doba, T. Ichikawa, and H. Yoshida, Bull Chem. Soc. Jpn., 50, 3124 (1977).

10. A. R. Schultz, P. I. Roth, and G. B. Rathmann, $J$. Polym. Sci., 22, 295 (1956).

11. M. Tabata, T. Miyazawa, O. Kobayashi, and J. Sohma, Chem. Phys. Lett., 73, 178 (1980).

12. M. Tabata and J. Sohma, Eur. Polym. J., 16, 589 (1979).

13. S. Noda, Y. Ohta, and H. Yoshida, Bull Chem. Soc. Jpn., 52, 1916 (1979).

14. S. Terabe, K. Kuruma and R. Konaka, J. Chem. Soc., Perkin Trans. 2, 1252 (1972).

15. K. Hirota, "Riron Yuki Kagaku (Theoretical Organic Chemistry)" Asakura Shoten, Tokyo, 1951.

16. E. W. Montroll, J. Am. Chem. Soc., 63, 1215 (1941).

17. M. Sakaguchi and J. Sohma, Adv. Polym. Sci., 20, 111 (1976). 